TI 2008-118/2

Tinbergen Institute Discussion Paper

White Knights and the Corporate Governance of Hostile Takeovers

Riccardo Calcagno'

Sonia Falconieri2

' VU University Amsterdam, and Tinbergen Institute;

2 Brunel University. 


\section{Tinbergen Institute}

The Tinbergen Institute is the institute for economic research of the Erasmus Universiteit Rotterdam, Universiteit van Amsterdam, and Vrije Universiteit Amsterdam.

Tinbergen Institute Amsterdam

Roetersstraat 31

1018 WB Amsterdam

The Netherlands

Tel.: +31(0)205513500

Fax: $+31(0) 205513555$

Tinbergen Institute Rotterdam

Burg. Oudlaan 50

3062 PA Rotterdam

The Netherlands

Tel.: + $31(0) 104088900$

Fax: $+31(0) 104089031$

Most TI discussion papers can be downloaded at http://www.tinbergen.nl. 


\title{
White knights and the corporate governance of hostile takeovers*
}

\author{
Riccardo Calcagno $^{\dagger} \quad$ Sonia Falconieri ${ }^{\ddagger}$
}

December 12, 2008

\begin{abstract}
We analyze the dynamics of takeover contests where hostile raiders compete against white knights involved by a lead blockholder of the target firm (the incumbent). We assume that the incumbent has the power to bargain with the potential bidders to set a minimum takeover price. We characterize the conditions under which a white knight wins the takeover contest despite the smaller value of its synergies as compared to those of the hostile bidder. The paper provides a new explanation for the reason why we observe so few hostile takeovers in reality; moreover, it sheds some light on the effectiveness of white knights as an anti-takeover device and the role played by leading minority blockholders in the market for corporate control.
\end{abstract}

*We would like to thank Vasso Ioannidou, Maria Fabiana Penas and Paul Sengmueller for their useful comments, as well as the seminar participants at the University of Groningen and the University of Tilburg.

†VU University Amsterdam and Tinbergen Institute. Email: rcalcagno@feweb.vu.nl

${ }^{\ddagger}$ Brunel University. Email: s.falconieri@brunel.ac.uk 


\section{Introduction}

Since the seminal paper of Manne (1965) changes in corporate control are considered to be a key mechanism of corporate governance ${ }^{1}$. However, the effectiveness of the market for corporate control as a disciplinary device for managerial misbehaviour crucially relies on the existence of credible hostile takeover threats. In practice, firms have been endowed over the time with several different anti-takeover measures to protect themselves against undesired, or sometimes inefficient, hostile takeovers. Among these, white knight intervention is effectively one of the most common devices particularly in Europe (Kästle and Trappehl, (2006)) $)^{2}$.

In this paper, we study the impact of two possible anti-takeover devices on the outcome of a takeover contest, namely the intervention of a friendly white knight and the existence of a dominant blockholder, who has control over the negotiations of the offers with the bidders. This question is particularly important in the light of the current debate among academics as well as regulators on how to design anti-takeover measures in order not to undermine the effectiveness of the market for corporate control. Additionally, the role of white knights has received a lot of attention from the financial press in recent years following some high-profile cases ${ }^{3}$.

We show that the presence of a leading minority shareholder controlling the bargaining process may result in an inefficient allocation of control. More precisely, owing to the expected loss of his private benefits of control in the event of a takeover by the hostile bidder, the incumbent turns to be a tougher bargainer with the raider than with the white knight thereby creating scope even for a white knight with lower synergies than the raider to win the takeover auction. Furthermore, we show that the threat itself of an ex-post intervention of a white knight may be sufficient to prevent the raider from launching an unsolicited bid. Thus our paper provides a possible explanation for the reason why we observe so few hostile takeovers, particularly in Europe.

Previous papers (Burkart et al. (2000); Harris, (1990)) have shown that the presence of a leading minority blockholder in the target firm can make the takeover harder. This because the minority blockholder, anticipating a loss of private benefit of control in the event of a successful hostile takeover, is typically a tougher bargainer than the other

\footnotetext{
${ }^{1}$ This view has been subsequently further strengthened by several other papers e.g. Grossmann and Hart (1980) and Franks and Meyer (1996). See also Burkart and Panunzi (2008) for an comprehensive review of the literature on takeover and the market for corporate control.

${ }^{2}$ The EU Take-over Directive 2004/25/EG for instance has issued guidelines aiming at prohibiting interference during a take-over. Specifically, the directive suggests to eliminate any prospective defence and to only allow the search for a white knight. As it is usual for EU Directives, each member state thas he possibility to opt-out and keep its own current regulation.

${ }^{3}$ Some recent and well knows examples of hostile takeovers in Europe where a white knight has been involved by the target include: Arcelor(target-T)/Mittal(raider-R)/Severstal(white knight-WK); Schering(T)/Merck(R)/Bayer(WK) and BAA(T)/Ferrovial(R)/Goldman Sachs(WK) (see Kästle and Trapphel (2006)). See also Section 4 for a more detailed discussion on the characteristics of these takeovers.
} 
shareholders.

In a recent paper, Aktas et al. (2008) investigate the impact of ex-ante competition on the bidding strategy of the initial bidder in friendly takeovers. Similarly to our model, they show that the initial (friendly) bid is affected by the potential competition of other bidders. However, in their model it is the number of potential competitors in the subsequent stages that affects the opening bid, whereas we show that the existence of just one potential, friendly competitor may force an hostile raider to increase the takeover premium and possibly force him out of the contest. Also, in Aktas et al. (2008) the competitor with the highest synergy always wins the auction, which is not the case in our model. Our results then cast a doubt on the ability of the market to allocate control efficiently when we take into account the contestants' bidding strategies.

In the literature there is a growing research interest in the specific dynamics of takeover contests. Eckbo (2008) points out that "in a very real sense, merger negotiations occur in the shadow of an auction, so the expected auction outcome affects the bargaining power of the negotiation parties." [pag. 3]. And Boone and Mulherin (2007) stress the importance of understand the role of what they define the "private" part of a takeover process in order to draw conclusions on the efficiency of the market for corporate control.

In this paper we present a model where an unsolicited bid is made for a target firm which is characterized by a leading blockholder (incumbent) that enjoys some private benefits of control ${ }^{4}$. The incumbent believes he would lose such control benefits if the raider takes over the firm, labelling then this first bid as hostile. Consequently he has an incentive to invoke a friendly bidder to compete against the hostile raider. At the moment of his opening bid, the raider anticipates that with some probability he may face a competitor, considered as friendly by the incumbent. We then design the takeover contest as a particular ascending auction where the bids at each round result from a bargaining between the leading blockholder and the current bidder. The idea of modelling the interaction between the leading blockholder and the bidder as a bargaining process is borrowed and adapted from Harris (1990). However, the innovative contribution of our paper is to combine the bargaining process with an English auction where the raider and the white knight compete one against the other for the control of the target company. Using this new framework we are able to characterize the conditions under which the threat of a white knight intervention at a later stage is sufficient to prevent a more efficient hostile bid. Furthermore, we derive the conditions under which the white knight is able to overbid the raider and take control of the target firm despite her lower synergy.

Finally, the present paper sheds light on the mechanism leading to the determination of takeover bids, when the target firm has a leading minority blockholder who leads the takeover negotiation.

Our model identifies several dimensions that play a crucial role in determining the outcome of the takeover contest and leads to precise empirical predictions. Specifically:

\footnotetext{
${ }^{4}$ The leading blockholder can potentially be the target management, as in Harris (1990).
} 
- The higher the likelihood of a white knight intervention after a hostile bid, the higher will be the takeover premium offered by the hostile raider;

- The same effect holds for an increase of the incumbent's private benefits of control. In general, target shareholders earn in terms of higher takeover premium whenever the presence of the white knight does not prevent the hostile raider from launching his first bid;

- The higher the initial hostile bid, the lower the probability to observe a successive white knight intervention;

- The higher the initial hostile bid, the higher the synergy of a white knight, if she intervenes; hence, the higher the ex-post performance in case of a success of the friendly bidder;

- The ex-post performance of the firms merged with a white knight following a high first hostile bid should be higher than the ex-post performance of firms merged with a white knight who defeated a very low hostile bid.

The paper is structured as follows: in the next section we spell out the details of the model and the takeover contest. Section 3 derives the optimal bidding strategies of the two contestants. In Section 4 we discuss the empirical implications that can be drawn from our model. Section 5 introduces an extension. Finally, Section 6 concludes.

\section{The model}

Consider a model with three risk-neutral agents: a target firm $T$ with a leading minority blockholder denoted by $I$ and an otherwise dispersed ownership; a hostile raider $H$; and a white knight $W K$. The hostile bidder and the white knight compete for the control over $T$. Due to the dispersed ownership structure of firm $T$, the minority block $\beta$ owned by $I$ entitles a real control authority over $T$ to its owner (see for example Burkhart, Gromb and Panunzi (2000)): hence, the control is transferred to the raider through a sale of the controlling block $\beta$. This assumption can be motivated in several different ways: we can think that $\beta$ is effectively a controlling stake (e.g. $\beta$ is close to 50 percent of the total amount of shares); or that the bidder cannot shop around for shares because $T$ is a private equity firm or because it would be more expensive to buy a controlling stake $\beta$ from small shareholders due to their free riding behavior (Grossman and Hart (1980), and Burkart et al. (2000)).

We now spell out the details of the takeover process.

The Firms - The process starts at time $t=0$ when all firms values are normalized to zero. At $t=0 \mathrm{H}$ may offer an unsolicited takeover bid for the incumbent block $\beta$ of firm $T$. The value of each share of $T$ for $H$ is equal to $R_{H}$ which represents the present value of the future cash flows of the conglomerate originated by the acquisition of $T$; equivalently, $R_{H}$ is equal to the present value of the (private) synergies that $H$ expects 
to gain by acquiring a share of $T^{5}$. The synergy $R_{H}$ is commonly known across the participants.

At the moment of making his first bid the raider $H$ knows that with probability $p$ a second bidder, $W K$, possibly invoked by $I$, may enter the takeover contest in the next period, i.e. at $t=1$, and make a counteroffer. At $t=0, H$ also knows that the private valuation (synergy) of a share of firm $T$ for $W K$, denoted by $R_{W K}$, is distributed according to a uniform c.d.f $F$ on the support $\left[0 ; R_{H}\right]$ and density function $f$. The synergy of the white knight can be interpreted as the value of avoiding the negative externality that a merger between $H$ and $T$ would have on $W K{ }^{6}{ }^{6}$ If $W K$ steps in at $t=1$, then her valuation will become public across the participants ${ }^{7}$.

Additionally, we assume that a merger between $H$ and $W K$ is never profitable and that ex- ante and ex-post side-payments from $T$ to $W K$ are not allowed: this implies that $W K$ will offer at most $R_{W K}$ for each share of $T .^{8}$

The leading blockholder - The leading blockholder (or incumbent) $I$ has a controlling stake $\beta$ in company $T$ and derives control benefits equal to $B^{9}$. Note that in practice the role of leading blockholder could also be played by the target management. What matters for our purposes is that $I$ is pivotal to the transfer of control whereas all other shareholders are atomistic. We assume that $I$ loses his private benefits of control if the the firm is taken over by the hostile raider whereas he will be able to maintain them in case of a success of the friendly bidder. This may happen because, for instance, $W K$ will let $I$ continue to manage the company, or she will allow him to sit in the Board of Directors with strong supervision powers. Due to the free-riding behavior of atomistic shareholders (Grossman and Hart (1980)), for each bidder is more convenient to purchase the stake $\beta$ of the incumbent in order to gain control over the company than to acquire it from the dispersed shareholders (Burkart et al. (2000)). Consequently, the bidders will have to negotiate the offer with $I$ at each stage of the process in the way detailed below.

The bidding process - We denote with $b_{t}^{\mathrm{J}}$ the publicly known offer of bidder $j=$ $H, W K$ at time $t$ for a share of $T^{10}$. The offer needs to receive the approval of the

\footnotetext{
${ }^{5}$ The common value part of the target firm $T$ is normalized to zero and commonly known across participants.

${ }^{6}$ This interpretation is consistent with the "pre-emptive" theory of mergers by Fridolfsson and Stennek (2005).

${ }^{7}$ This is not a crucial assumption for our results. What matters is that $I$ knows $R_{W K}$ and this reasonably occurs during the barganing negotiation.

${ }^{8}$ The rationale for this assumption is that we want to check whether there exist conditions under which the white knight wins the takeover contest even in the absence of a side payment from the target management. If this is true, then it will be a fortiori true in the case she receives a side payment from $T$ 's management. Examples of such side payments are the supply of raw material at a price below the market price or the so-called "crown jewels" transferred from $T$ to the taking over firm after the acquisition. Additionally this is consistent with the current regulation that forbids the target firm from providing financial support to the white knight. (Kastel and Trapphel, 2006)

${ }^{9}$ See Burkart et al.(2000) for a rationale of why minority blockholder may be able to extract private benefits of control.

${ }^{10}$ Thus, the offer for the entire block $\beta$ is equal to $\beta b_{t}^{\mathrm{J}}$. From now on, we will reason in terms of offer
} 
incumbent i.e. it needs to be higher than a minimum threshold at which $I$ will be willing to tender his shares. This minimum bid is obtained as the Nash bargaining solution between $I$ and the bidder for the splitting of the synergy $R_{j}{ }^{11}$

At $t=0, H$ decides whether to initiate the takeover contest or not: if he does, he offers $b_{0}^{\mathrm{H}}$. Then at $t=1$ a white knight decides whether to step in and make a counteroffer which has to be higher than the hostile outstanding bid: $b_{1}^{\mathrm{WK}}>b_{0}^{\mathrm{H}}$. From $t=1$ onward, the control contest unfolds as an English auction, i.e. with subsequent bids of $H$ and $W K$ respectively.

At each round of the game the minimum bid is the result of a Nash bargaining between $I$ and the current bidder to split the surplus generated by the control transfer. This surplus is proportional respectively to $R_{H}$ or $R_{W K}$ depending on whom $I$ is bargaining with. Suppose that at a given time $t$ the outstanding bid is $b_{t}^{\mathrm{H}}$. If $I$ accepts the offer and tenders his shares he obtains a monetary payoff $\beta b_{t}^{\mathrm{H}}$ but he also loses his private benefits of control $B$. If the outstanding bid is a friendly bid $b_{t}^{\mathrm{WK}}$, and $I$ accepts the white knight's offer he cashes in $\beta b_{t}^{\mathrm{WK}}$ and also keeps his private benefits $B$.

We also need to evaluate the parties' disagreement payoffs, i.e. the parties' payoff if the takeover fails. Intuitively, for the two bidders the disagreement payoffs are simply their initial values zero. Conversely, for the incumbent the disagreement payoff at each round is represented by his current outside option, that is the payoff he would get if he accepted the outstanding bid. More precisely, if $I$ is bargaining with $W K$ and the outstanding hostile bid is $b_{t}^{\mathrm{H}}$, his outside options is measured by $\beta b_{t}^{\mathrm{H}}-B$, i.e. the monetary payoff minus the loss of the control benefits. If $I$ is instead bargaining with $H$ and the friendly outstanding bid is $b_{t+1}^{\mathrm{WK}}$, then his disagreement payoff would be $\beta b_{t+1}^{\mathrm{WK}}$, i.e. the monetary payoff she would get by selling to $W K$ (there is no loss of control benefit in this case). Figure 1 summarizes the timeline of the events.

\section{The solution of the takeover contest}

In this section we describe in details the different stages of the bidding process and define the optimal bidding strategies of both the hostile bidder and the white knight. We then derive the conditions under which the white knight wins the auction.

The following preliminary result will be useful in the subsequent analysis:

Lemma 1 If $H$ and/or $W K$ know they win the takeover auction for sure at time $t^{\prime}>t$ offering a price $b_{t^{\prime}}$ then they will offer such a price at $t$. Similarly if $H$ or $W K$ are sure to lose the auction at time $t^{\prime}>t$ given the outstanding bid $b_{t}$, then they will pull out from the game at time $t$.

per share.

${ }^{11}$ In the context of our model the Nash bargaining solution is consistent with alternative dynamic bargaining solutions (a proof can be requested to the authors). 


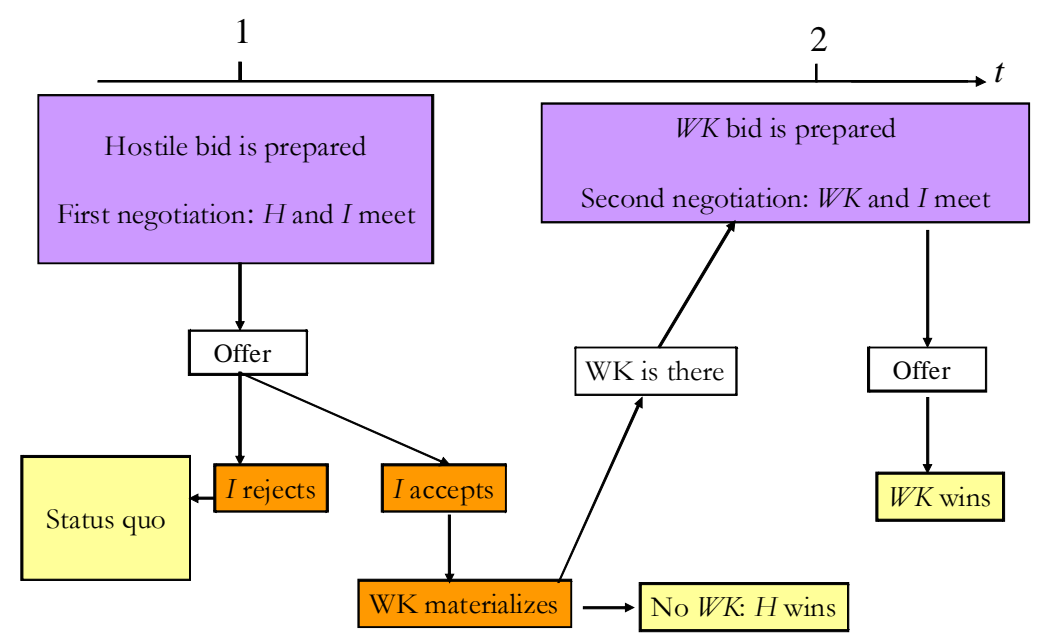

Figure 1:

Proof: The above statement is quite intuitive in our model where the auction game does not involve a refinement of the bidder's information set from one round to another. After $t=1$, when the uncertainty about the existence of a white knight is resolved, no additional information is produced during the takeover process. Therefore, waiting a later stage to make an offer will only raise the price the bidder has to pay in order to win. Similarly, if one of the bidders knows for sure that he will certainly lose the auction then he will exit the game immediately. ${ }^{12}$

Given Lemma 1 we can focus on the first two rounds of the game. We construct an equilibrium in which either $W K$ steps in at $t=1$ with a winning bid $\widehat{b}_{1}^{\text {WK }}$ or $H$ wins the takeover contest with a bid $\widehat{b}_{0}^{\mathrm{H}}$ at $t=0$. We also characterize the conditions under which the threat of a white knight intervention is sufficient to prevent a hostile bidder to initiate the takeover.

The game is solved backward starting from the white knight's bid at $t=1$.

\subsection{The white knight optimal strategy}

In $t=1$ the outstanding offer by $H$ is denoted by $b_{0}^{\mathrm{H}}$ and $I$ is willing to sell his stake $\beta$ at $\beta b_{0}^{\mathrm{H}}$ in the absence of a higher bid. Note that, given $b_{0}^{\mathrm{H}}$, only white knights that can profitably offer more than $b_{0}^{\mathrm{H}}$ enter the game, i.e. only white knights with synergy $R_{W K} \in\left(b_{0}^{\mathrm{H}}, R_{H}[\right.$.

\footnotetext{
${ }^{12}$ This holds true under our assumption of no side payment from $M_{T}$ to $W K$ and given that the bidders' utility does not depend on the price paid by the other contestant (see Section 5 for a complete analysis of this case).
} 
Then, in $t=1$ a Nash bargaining round between $I$ and $W K$ takes place to determine the minimum acceptable bid for $M_{T}$. Recall that the disagreement payoff of $I$ is equal to $\beta b_{0}^{\mathrm{H}}-B$, because in case of a takeover by $H$, the target management will loose his private benefit $B$. The disagreement payoff for $W K$ is equal to zero. The total surplus that can be split between the two bargainers is $\beta R_{W K}$. We denote the shares of the surplus going to $T$ and to $W K$ by $\left(\delta_{1}, 1-\delta_{1}\right)$ respectively.

These shares are the optimal solutions of the following Nash bargaining problem between $M_{T}$ and $W K$ at $t=1$ :

$$
\max _{\delta_{1}}\left[\beta\left(1-\delta_{1}\right) R_{W K}\right]\left[\delta_{1} \beta R_{W K}-\left(\beta b_{0}^{\mathrm{H}}-B\right)\right]
$$

The solution of (1) is:

$$
\delta_{1}^{*}=\frac{1}{2}+\frac{b_{0}^{\mathrm{H}}}{2 R_{W K}}-\frac{B}{2 \beta R_{W K}}
$$

and hence the minimum bid of $W K$ accepted by $I$ is $b_{1} \geq \delta_{1}^{*} R_{W K}$.

This provides us a first boundary on the white knight bid:

$$
b_{1} \geq \delta_{1}^{*} R_{W K}
$$

provided that $b_{1}^{\mathrm{WK}}$ is not larger than the white knight value $R_{W K}$, which, as before, requires that $\delta_{1}^{*}<1$. This is in turn equivalent to:

$$
\begin{aligned}
\frac{b_{0}^{\mathrm{H}}}{2 R_{W K}}-\frac{B}{2 \beta R_{W K}} & <\frac{1}{2} \\
R_{W K} & >b_{0}^{\mathrm{H}}-\frac{B}{\beta}
\end{aligned}
$$

This latter condition is always verified for white knights with valuations $R_{W K} \in$ $\left[b_{0}^{\mathrm{H}}, R_{H}[\right.$.

We then have to derive the white knight's optimal bid given the above constraints. The result is stated in the next proposition.

Proposition 1 Assume the type of $W K$ is $R_{W K} \in\left[b_{0}^{\mathrm{H}}, R_{H}[\right.$. The optimal bid for $W K$ of type $R_{W K}>b_{1}^{*}$ is $b_{1}^{*}=\max \left\{R_{H}-\frac{B}{\beta}, b_{0}^{\mathrm{H}}+\varepsilon, \delta_{1}^{*} R_{W K}\right\}$, where

$$
\delta_{1}^{*}=\frac{1}{2}+\frac{b_{0}^{\mathrm{H}}}{2 R_{W K}}-\frac{B}{2 \beta R_{W K}}
$$

and $\varepsilon>0$ arbitrarily small.

Proof: in the Appendix.

The intuition behind the proof of Proposition 1 is the following: $W K$ can overtake $H$ with certainty only if her bid $b_{1}^{W K}$ gives $I$ an outside option high enough to make impossible for $H$ to find an agreement with $I$ in the next round of bargaining. Formally, this requires $b_{1}^{W K}$ to be high enough to make $\delta_{2} \geq 1$, where $\delta_{2}$ is the quota of surplus 


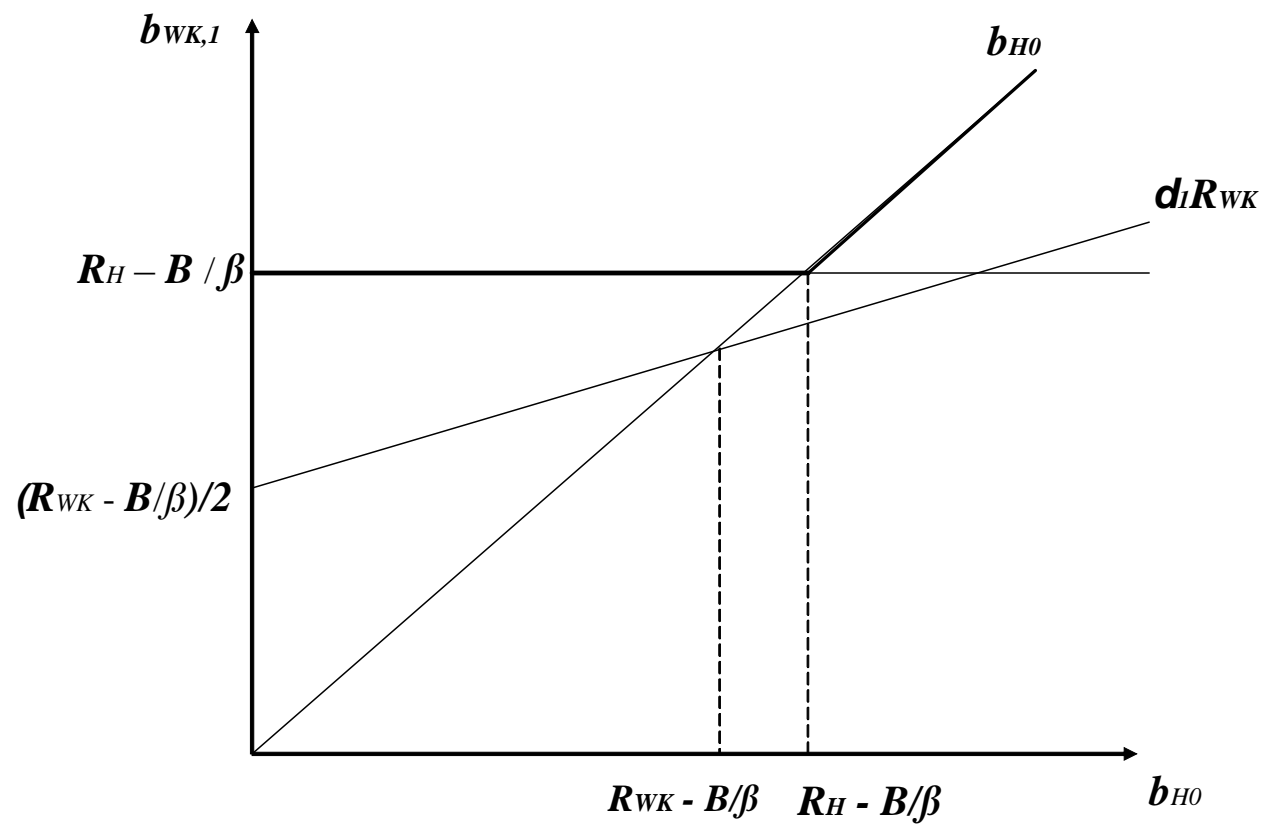

Figure 2:

going to $I$ in a Nash bargaining with $H$ at period two. As in any Nash bargaining problem, $\delta_{2}$ is increasing in the outside option of $W K$, which at $t=2$ is determined by the outstanding bid $b_{1}^{W K}$ offered by $W K$ at $t=1$. A higher $b_{1}^{W K}$ makes $I$ tougher in later negotiations with $H$, at the limit excluding the possibility of a mutually profitable agreement.

The table below summarizes the conditions under which $W K$ of type $R_{W K} \in$ $\left[b_{1}^{*}, R_{H}[\right.$ wins the takeover auction:

\begin{tabular}{|l|}
\hline$b_{1}^{*} \geq R_{H}-\frac{B}{\beta}$ to ensure that $\delta_{2}\left(b_{1}^{W K}\right) \geq 1$ \\
\hline$b_{1}^{*}>b_{0}^{\mathrm{H}}$ to beat the outstanding bid by $H$ \\
\hline$b_{1}^{*} \geq \delta_{1} R_{W K}$ for $I$ to accept the bid (with $\left.\delta_{1}<1, \forall R_{w k} \geq b_{0}^{\mathrm{H}}\right)$ \\
\hline
\end{tabular}

Figure 2 illustrates the best reply function $b_{1}^{*}\left(b_{0}^{\mathrm{H}}\right)$ in bold.

From the figure, we can clearly see that only the first two conditions matter. This is also stated in the following Lemma. 
Lemma $2 A$ white knight of type $R_{W K} \geq b_{1}^{*}$ wins the takeover contest at $t=1$ with a bid $b_{1}^{*}=\max \left\{R_{H}-\frac{B}{\beta}, b_{0}^{\mathrm{H}}+\varepsilon\right\} \varepsilon>0$ arbitrarily small.

Proof: in the Appendix.

Only $W K$ with types $R_{W K} \geq \max \left\{R_{H}-\frac{B}{\beta}, b_{0}^{\mathrm{H}}\right\}$ can profitably enter the takeover auction. White knights with lower synergies can not win the takeover with positive profits, hence, by Lemma 1, they stay out of the auction.

A useful way to describe the best reply of $W K$ at $t=1$ to $b_{0}^{\mathrm{H}}$ is to introduce the threshold function $t\left(b_{0}^{\mathrm{H}}\right)$ where $t\left(b_{0}^{\mathrm{H}}\right)$ is the highest type of white knight the raider can eliminate with certainty from the takeover contest given the raider's initial bid $b_{0}^{\mathrm{H}}$. This function $t\left(b_{0}^{\mathrm{H}}\right)$ can be easily derived from Lemma 2 and is formally defined as follows:

Corollary 1 The function $t\left(b_{0}^{\mathrm{H}}\right)$ is defined as

$$
t\left(b_{0}^{\mathrm{H}}\right)=\left\{\begin{array}{cc}
R_{H}-\frac{B}{\beta} & \text { for } b_{0}^{\mathrm{H}} \leq R_{H}-\frac{B}{\beta} \\
b_{0}^{\mathrm{H}} & \text { for } b_{0}^{\mathrm{H}} \geq R_{H}-\frac{B}{\beta}
\end{array}\right.
$$

Thus, any initial premium initially offered by $H$ preempts a white knight with synergy $R_{W K}<R_{H}-\frac{B}{\beta}$ to enter the takeover contest. For $W K$ with higher types $R_{W K} \geq R_{H}-\frac{B}{\beta}$ the strategic interaction between the two contestants is similar to an ascending auction.

\subsection{The hostile initial bid}

At time $t=0$ the hostile raider $H$ decides whether to open the control contest or not; if he decides to enter, then he has to choose the first offer $b_{0}$. His strategy correctly takes into account the best reply $t\left(b_{0}\right)$ of $W K$ contained in (4); in other words, he rationally anticipates that for any initial bid $b_{0}$, white knights with type $R_{W K}<t\left(b_{0}\right)$ will stay out of the contest.

Given that $R_{W K}$ is uniformly distributed on the interval $\left[0, R_{H}\right]$, so $F(x)=\frac{x}{R_{H}}$ we can state the raider's optimization problem at $t=0$ as follows ${ }^{13}$ :

$$
\begin{array}{ll} 
& \max _{b_{0}}(1-p)\left(R_{H}-b_{0}\right)+p\left(\frac{t\left(b_{0}\right)}{R_{H}}\left(R_{H}-b_{0}\right)\right) \\
\text { s.t. }: & b_{0} \geq \delta_{0}^{*} R_{H}
\end{array}
$$

where $\delta_{0}^{*}$ is the solution of the following Nash bargaining problem:

\footnotetext{
${ }^{13}$ When $H$ bids for the stake $\beta$ of $T$ his expected payoff is equal to

$$
(1-p) \beta\left(R_{H}-b_{0}\right)+p\left(\frac{t\left(b_{0}\right)}{R_{H}} \beta\left(R_{H}-b_{0}\right)\right)
$$

which is proportional to a factor $\beta$ to the one in the text. The solutions of the two problems then coincide.
} 


$$
\max _{\delta_{0}}\left[\beta\left(1-\delta_{0}\right) R_{H}\right]^{1-p\left(1-\frac{t\left(b_{0}\right)}{R_{H}}\right)}\left[\beta \delta_{0} R_{H}-B\right]^{p\left(1-\frac{t\left(b_{0}\right)}{R_{H}}\right)}
$$

In other words, $(1-p)\left(R_{H}-b_{0}\right)$ is the expected payoff of $H$ if a $W K$ does not step in in the next round, which occurs with probability $p$, whereas $p\left(\frac{t\left(b_{0}\right)}{R_{H}}\left(R_{H}-b_{0}\right)\right)$ is his payoff when $W K$ exists but has a synergy $R_{W K} \leq t\left(b_{0}\right)$.

In order to solve problem (5) we first explicitly determine the solution of (6) between $H$ and $I$; we then proceed to solve the unconstrained maximization of $H$ 's expected profit; and finally we check when the constraint $b_{0} \geq \delta_{0}^{*} R_{H}$ is binding.

The Nash bargaining solution $\delta_{0}^{*}$ depends crucially on the relative bargaining power of $H$ and $I$. Intuitively, the bargaining power of $I$ should increase with the possibility for $I$ to obtain a better price from a white knight at a later stage. This event occurs with probability $p \operatorname{Pr}\left(R_{W K} \geq t\left(b_{0}\right)\right)=p\left(1-\frac{t\left(b_{0}\right)}{R_{H}}\right)$. For analytical tractability we assume that the bargaining power of $I$ is indeed equal to the probability of a successful ex-post intervention of $W K$.

The next Proposition contains the key result about the optimal hostile entry bid.

Proposition 2 For $B \geq \beta R_{H}$ the control contest is not initiated by $H$, and $I$ stays in place. For $B \in\left[\frac{\beta R_{H}}{2}, \beta \bar{R}_{H}\right]$ the unique solution of (5) is $b_{0}^{*}=\delta_{0} R_{H}$ where $\left.\delta_{0} \in\right] \frac{B}{\beta R_{H}}$, 1[ solves:

$$
1+\beta \frac{\left(1-\delta_{0}\right) R_{H}}{\delta_{0} \beta R_{H}-B}+\log \left(\frac{\beta\left(1-\delta_{0}\right) R_{H}}{\delta_{0} \beta R_{H}-B}\right)=\frac{1}{p\left(1-\delta_{0}\right)}
$$

For $B\left[2+p\left(1-\frac{B}{\beta R_{H}}\right)\right]<\beta R_{H}\left(\Rightarrow 2 B<\beta R_{H}\right)$ then the unique solution of $(5)$ is $b_{0}^{*}=\delta_{0} R_{H}$ where

$$
\delta_{0}=\frac{B}{\beta R_{H}}\left[1+p\left(1-\frac{B}{\beta R_{H}}\right)\right]<1
$$

Proof: The proof is done in several steps.

We start by noticing that the function $t\left(b_{0}\right)$ is not differentiable at $b_{0}=R_{H}-\frac{B}{\beta}$ : this forces us to solve (6) looking separately at the solutions in two intervals: first look for solutions $b_{0} \leq R_{H}-\frac{B}{\beta}$, and then for solutions in the range $b_{0} \geq R_{H}-\frac{B}{\beta}$.

Lemma 3 For $B\left[2+p\left(1-\frac{B}{\beta R_{H}}\right)\right]<\beta R_{H}\left(\Rightarrow 2 B<\beta R_{H}\right)$ then the unique solution of (5) is $b_{0}^{*}=\delta_{0} R_{H}$ where

$$
\delta_{0}=\frac{B}{\beta R_{H}}\left[1+p\left(1-\frac{B}{\beta R_{H}}\right)\right]<1
$$


Proof: We constrain ourselves to the range of $b_{0} \leq R_{H}-\frac{B}{\beta}$, where $t\left(b_{0}\right)=R_{H}-\frac{B}{\beta}$. Substituting for $t\left(b_{0}\right)$ in the Nash bargaining problem and taking logs we obtain:

$$
\begin{aligned}
& \max _{\delta_{0}}\left(1-p\left(1-\frac{R_{H}-\frac{B}{\beta}}{R_{H}}\right)\right) \log \left(\beta\left(1-\delta_{0}\right) R_{H}\right)+p\left(1-\frac{R_{H}-\frac{B}{\beta}}{R_{H}}\right) \log \left(\beta \delta_{0} R_{H}-B\right) \\
& \max _{\delta_{0}}\left(1-p \frac{B}{\beta R_{H}}\right) \log \left(\beta\left(1-\delta_{0}\right) R_{H}\right)+p\left(\frac{B}{\beta R_{H}}\right) \log \left(\beta \delta_{0} R_{H}-B\right)
\end{aligned}
$$

whose f.o.c. is:

$$
\begin{aligned}
\frac{p B}{\beta \delta_{0} R_{H}-B} & =\frac{1-p \frac{B}{\beta R_{H}}}{1-\delta_{0}} \\
\delta_{0} & =\frac{B}{\beta R_{H}}\left(1+p-p \frac{B}{\beta R_{H}}\right)
\end{aligned}
$$

Since at this point $b_{0}=\delta_{0} R_{H}$, this solution is consistent to our initial requirement $b_{0} \leq R_{H}-\frac{B}{\beta}$ iff

$$
\frac{B}{\beta R_{H}}\left(1+p-p \frac{B}{\beta R_{H}}\right) \leq 1-\frac{B}{\beta R_{H}}
$$

which can be rewritten as $\frac{B}{\beta R_{H}}\left[2+p\left(1-\frac{B}{\beta R_{H}}\right)\right] \leq 1$. Notice that a necessary condition for the last inequality to be satisfied is $\frac{B}{\beta R_{H}}<1 / 2$. Notice also that if $\frac{B}{\beta R_{H}}\left[2+p\left(1-\frac{B}{\beta R_{H}}\right)\right] \leq$ 1 then for sure $\frac{B}{\beta R_{H}}\left[1+p\left(1-\frac{B}{\beta R_{H}}\right)\right]=\delta_{0}<1$.

We now proceed studying the expected profit for $H$, in the range of bids $b_{0} \in$ $\left[0, R_{H}-\frac{B}{\beta}\right]$. Substituting $t\left(b_{0}\right)=R_{H}-\frac{B}{\beta}$ into $(1-p)\left(R_{H}-b_{0}\right)+p\left(\frac{t\left(b_{0}\right)}{R_{H}}\left(R_{H}-b_{0}\right)\right)$ we obtain

$$
E\left[\Pi_{H, 0}\left(b_{0}\right)\right]=(1-p)\left(R_{H}-b_{0}\right)+p\left(\frac{R_{H}-\frac{B}{\beta}}{R_{H}}\left(R_{H}-b_{0}\right)\right)
$$

which is clearly monotone decreasing in $b_{0}$ in the interval $\left[0, R_{H}-\frac{B}{\beta}\right]$. The constraint $b_{0} \geq \delta_{0} R_{H}$ is then binding.

We now turn to solutions in the range $b_{0} \geq R_{H}-\frac{B}{\beta}$, where $t\left(b_{0}\right)=b_{0}$.

Lemma 4 For $\left.B \in] \frac{\beta R}{2}, \beta R_{H}\right]$ the unique solution of (5) is $b_{0}^{*}=\delta_{0} R_{H}$ where $\delta_{0} \in$ ]$\frac{B}{\beta R_{H}}, 1[$ solves:

$$
1+\beta \frac{\left(1-\delta_{0}\right) R_{H}}{\delta_{0} \beta R_{H}-B}+\log \left(\frac{\beta\left(1-\delta_{0}\right) R_{H}}{\delta_{0} \beta R_{H}-B}\right)=\frac{1}{p\left(1-\delta_{0}\right)}
$$

Proof: Substituting for $t\left(b_{0}\right)=b_{0}$ in the Nash bargaining problem and taking logs we obtain:

$$
\max _{\delta_{0}}\left(1-p\left(1-\delta_{0}\right)\right) \log \left(\beta\left(1-\delta_{0}\right) R_{H}\right)+p\left(1-\delta_{0}\right) \log \left(\beta \delta_{0} R_{H}-B\right)
$$


and the f.o.c.:

$$
\begin{aligned}
& p \log \left(\beta\left(1-\delta_{0}\right) R_{H}\right)-\frac{1-p\left(1-\delta_{0}\right)}{\left(1-\delta_{0}\right)}-p \log \left(\beta \delta_{0} R_{H}-B\right)+\frac{p\left(1-\delta_{0}\right) \beta R_{H}}{\beta \delta_{0} R_{H}-B}=0 \\
& \log \left(\beta\left(1-\delta_{0}\right) R_{H}\right)-\log \left(\beta \delta_{0} R_{H}-B\right)=\frac{1-p\left(1-\delta_{0}\right)}{p\left(1-\delta_{0}\right)}-\frac{\left(1-\delta_{0}\right) \beta R_{H}}{\beta \delta_{0} R_{H}-B} \\
& \log \left(\frac{\beta\left(1-\delta_{0}\right) R_{H}}{\beta \delta_{0} R_{H}-B}\right)=\frac{1}{p\left(1-\delta_{0}\right)}-1-\beta \frac{\left(1-\delta_{0}\right) R_{H}}{\beta \delta_{0} R_{H}-B} \\
& 1+\beta \frac{\left(1-\delta_{0}\right) R_{H}}{\delta_{0} \beta R_{H}-B}+\log \left(\frac{\beta\left(1-\delta_{0}\right) R_{H}}{\delta_{0} \beta R_{H}-B}\right)=\frac{1}{p\left(1-\delta_{0}\right)}
\end{aligned}
$$

Notice that the $\log$ functions are defined only for $\left.\delta_{0} \in\right] \frac{B}{\beta R_{H}}, 1[$ : if one solution of the Nash bargaining problem exists, it lies in such an interval. Of course the interval ] $\frac{B}{\beta R_{H}}, 1\left[\right.$ is non empty only if $B<\beta R_{H}$.

Equation (7a) cannot be solved analytically, but one can show that there exists always a unique solution of (7a) in $] \frac{B}{\beta R_{H}}, 1[$. Indeed:

$$
\begin{aligned}
& \lim _{\delta_{0} \rightarrow 1^{-}} 1+\beta \frac{\left(1-\delta_{0}\right) R_{H}}{\delta_{0} \beta R_{H}-B}+\log \left(\frac{\beta\left(1-\delta_{0}\right) R_{H}}{\delta_{0} \beta R R_{H}-B}\right)=0 \\
& \lim _{\delta_{0} \rightarrow 1^{-}} \frac{1}{p\left(1-\delta_{0}\right)}=+\infty \\
& \lim _{\delta_{0} \rightarrow\left(\frac{B}{\beta R_{H}}\right)^{+}} 1+\beta \frac{\left(1-\delta_{0}\right) R R_{H}}{\delta_{0} \beta R R_{H}-B}+\log \left(\frac{\beta\left(1-\delta_{0}\right) R_{H}}{\delta_{0} \beta R R_{H}-B}\right)=+\infty \\
& \lim _{\delta_{0} \rightarrow\left(\frac{B}{\beta R R_{H}}\right)} \frac{1}{p\left(1-\delta_{0}\right)}=\frac{1}{p\left(1-\frac{B}{\beta R_{H}}\right)}>0
\end{aligned}
$$

and since both functions $1+\beta \frac{\left(1-\delta_{0}\right) R_{H}}{\delta_{0} \beta R_{H}-B}+\log \left(\frac{\beta\left(1-\delta_{0}\right) R_{H}}{\delta_{0} \beta R_{H}-B}\right)$ and $\frac{1}{p\left(1-\delta_{0}\right)}$ are continuous in $] \frac{B}{\beta R R_{H}}, 1\left[\right.$ they will certainly cross at some point $\delta_{0}$ interior to that interval. Notice that the solution to the f.o.c. (7a) will be then strictly higher than $\frac{B}{\beta R_{H}}$.

Of course we are left to check when such a solution is consistent, that is when $\delta_{0} R_{H} \geq R_{H}-\frac{B}{\beta}$ : since $\delta_{0}$ is strictly higher than $\frac{B}{\beta R_{H}}$ a necessary condition for this is that

$$
\frac{B}{\beta}>R_{H}-\frac{B}{\beta} \Leftrightarrow B>\frac{\beta R_{H}}{2}
$$

If we study the expected profit function $E\left[\Pi_{H, 0}\left(b_{0}\right)\right]=(1-p)\left(R_{H}-b_{0}\right)+p\left(\frac{t\left(b_{0}\right)}{R}\left(R_{H}-b_{0}\right)\right)$ when $t\left(b_{0}\right)=b_{0}$ we obtain:

$$
E\left[\Pi_{H, 0}\left(b_{0}\right)\right]=\left(R_{H}-b_{0}\right)\left(1-p+p \frac{b_{0}}{R_{H}}\right)
$$

which has a maximum at $b_{0}=R_{H}\left(1-\frac{1}{2 p}\right)$. For $B>\frac{\beta R_{H}}{2}$ we have that $R_{H}\left(1-\frac{1}{2 p}\right)>$ $R_{H}-\frac{B}{\beta}$, so such a maximum falls indeed in the region of bids with $t\left(b_{0}\right)=b_{0}$, and is 
then consistent with our starting point. However, for $B>\frac{\beta R_{H}}{2}: R_{H}\left(1-\frac{1}{2 p}\right)<\frac{B}{\beta}$, so the unconstrained optimal bid for $H$ is lower than $\delta_{0} R_{H}$ : the constraint imposed by the Nash bargaining solution is again binding, and $b_{0}^{*}=\delta_{0} R_{H}$, where $\delta_{0}$ solves (7a).

To conclude the proof of the proposition, we finally observe that for $B \geq \beta R_{H}$ the expected profit $E\left[\Pi_{H, 0}\left(b_{0}\right)\right]<0$ for any positive bid $b_{0} \geq 0$, hence $H$ does not initiate the control contest.

Proposition 2 above fully characterizes the behavior of raider $H$. First of all, high private benefits of control $B$ coupled with low blocks $\beta$ owned by $I$ offer a strong anti-takeover device, as in Harris (1990): only when $B<\beta R_{H}$ there is room for $H$ to profitably make a first, unsolicited bid.

The relative dimension of private benefits $B$ versus the incumbent's stake $\beta$ determines the level of the bids. When $\frac{B}{\beta}$ is relatively high (i.e. it belongs to $\left[\frac{R_{H}}{2}, R_{H}\right]$ ), the first bid $b_{0}^{*}$ is such that more than half of the synergies are appropriated by $I$. Moreover, if a subsequent bid by a white knight arises, this is only slightly higher than $b_{0}^{*}$. The incumbent $I$ is very tough in the bargaining with $H$ and manages to extract most of the surplus; $H$ does not offer more than it is needed to let $I$ agree to the deal since such a high offer is enough to scare off most of the (potential) white knights. On the contrary, when $\frac{B}{\beta}$ is relatively low (i.e. less than $\frac{R_{H}}{2}$ ), less than half of the synergies is appropriated by $I$. Also in this case $H$ does not make high preemptive offers to stop the potential subsequent intervention of a white knight. This happens because the probability $p$ of white knight intervention is sufficiently low, i.e. $B\left[2+p\left(1-\frac{B}{\beta R_{H}}\right)\right]<\beta R_{H} \Leftrightarrow p<\frac{\frac{\beta R_{H}}{B}-2}{1-\frac{B}{\beta R_{H}}}$, and for $H$ is optimal to take the chance of making a low offer and waiting whether ex-post a $W K$ with high synergies arise.

Proposition 2 also highlights that the opening bid by $H$ is a function of the three main parameters of the model the size of the private benefit of control $B$, the probability to that a white knight exists and steps in $p$; and the stake of the leading blockholder, $\beta$. It is thus interesting to study how the opening bid changes as these parameters change. The results of the comparative statics are collected in the next proposition.

Proposition 3 The takeover premium offered by $H$ increases with $p, B$ and decreases with $\beta$.

Proof: in the Appendix.

These results are consistent with the standard predictions of bargaining theory that in our case explain the level of the first bid. 


\section{Empirical Implications}

Although the empirical literature on mergers and acquisition is quite vast, ${ }^{14}$ there exist few studies that look specifically at the long-term performance of white knights' acquisitions (Niden (1993), Carroll et at. (1999)), and the results seem not to be conclusive $^{15}$.

The results obtained in the previous section provide some testable empirical implications that should contribute to better understand the features of takeover contest where there is a white knight intervention..In what follows, we list the main ones by linking them to the corresponding theoretical results in the previous analysis.

From proposition 2 , we know that for $B>\beta R_{H}$ there is no hostile bid.

Prediction 1: High private benefits of control by the incumbent and low inside ownership cause less hostile takeover threats.

From Proposition 3, we know that if there is a hostile bid, the entry hostile bid is equal to $b_{0}^{*}=\delta_{0} R_{H}<R_{H}-\frac{B}{\beta}$.

Prediction 2: The hostile bid $b_{0}^{*}$, if it is observed, is increasing in $\delta_{0}$, that is it is increasing in the private benefit of control $B$ and the probability of a white knight intervention $p$; it is instead decreasing in the incumbent ownership $\beta$.

Testing this prediction would require to build some proxy for the ex-ante probability of a white knight intervention. One possible way to measure $p$ could be to use some measures of business proximity between the target firm and other firms, e.g. board interlocks or other top-management links, cross-holding or other ownership links, existence of business alliances/partnerships/joint ventures with other firms.

Casual observation seems to document that the intervention of a white knight increases the initial bid and thus the takeover premium for the target firm as shown in the next table ${ }^{16}$ :

$\begin{array}{lllll}\text { TARGET } & \text { HOSTILE BIDDER } & \text { WHITE KNIGHT } & \text { INITIAL BID } & \text { FINAL BID } \\ \text { Schering } & \text { Merck } & \text { Bayer } & € 77 \mathrm{bn} & € 86 \mathrm{bn} \\ \text { Arcelor } & \text { Mittal } & \text { Severstal } & € 28.2 \mathrm{bn} & € 52.5 \mathrm{bn} \\ \text { Dofasco } & \text { Arcelor } & \text { Thyssen-Krupp } & \text { CAN } \$ 56 \mathrm{bn} & \text { CAN } \$ 71 \\ \text { BAA } & \text { Ferrovial } & \text { Goldman Sachs } & £ 8.1 \mathrm{bn} & £ 9.5 \mathrm{bn} \\ \text { Mannesmann } & \text { Vodafone } & \text { Vivendi* } & 43.7 \text { (shares) } & 58.98 \text { (shares) } \\ \text { Aventis } & \text { Sanofi } & \text { Novartis* } & 47.8 \mathrm{bn} \text { EUR } & 54.5 \mathrm{bn} \text { EUR }\end{array}$

\footnotetext{
${ }^{14}$ See for instance Burkart and Panunzi (2008) for a review and Martynova and Renneboog (2006) for a review of the literature on European mergers.

${ }^{15}$ Andrade et al. (2001) question the methodology used in many long-term event studies, and report that overall long-term abnormal returns for acquiring are considerably close to zero.

${ }^{16}$ Based on Kastle and Traepphel (2006).
} 
Proposition 1, together with Lemma 2 also prove that if a white knight enters the takeover contest, she offers a bid $b_{1}^{*}=\max \left\{\delta_{0} R_{H}, R_{H}-\frac{B}{\beta}\right\}$. As already explained, only white knights with synergies above $b_{1}^{*}$ can thus profitably enter the contest. The higher the price $b_{1}^{*}$, the lower the probability (ex-ante) to observe a friendly bid. Hence we can formulate these two additional testable implication is:

Prediction 3: The higher $b_{0}^{*}$, i.e. the initial hostile bid, the lower the probability to observe $W K$ 's interventions.

Prediction 4: The higher $b_{0}^{*}$, the higher should be the white knight synergy when $W K$ wins the contest. This in turn implies that the ex-post performance of the firms merged with a $W K$ following a high first hostile bid should be higher than the ex-post performance of firms merged with a $W K$ who defeated a very low hostile bid.

Finally, our results suggest that the potential intervention of a white knight may discourage an initial hostile offer. Since white knights are among the very few remaining legal anti-takeover measures in Europe, while this is not the case in the US, our paper provides a possible explanation of why hostile bids may be so rare in Europe.

\section{Allowing side payments between the target and the white knight}

We discuss here the consequences of allowing monetary transfers between $T$ and $W K$ in two different cases: the first is the existence of "crown jewels" (i.e. ex-post transfers from $T$ to $W K$ ); the second is the possibility of ex-ante side payments from $T$ to $W K$.

Intuitively, suppose $T$ and $W K$ agree that if $W K$ takes over, she receives a strictly positive payment (e.g. in the form of "crown jewels"). This would increase the ex-ante value of $T$ for $W K$ up to $R_{W K}^{\prime}$; however, as long as $R_{W K}^{\prime} \leq R_{H}$ with probability one, and such an agreement is anticipated correctly by $H$, the solution of the takeover contest remains the same as in section 3 , simply with a new distribution $F^{\prime}$ of $R_{W K}^{\prime}$.

The second extension introduces a form of collusion between $T$ and $W K$. Let us allow now side payments from $T$ to $W K$ of the following form: $T$ agrees to subsidize the cost of making a bid to $W K$, even if it is commonly known that $W K$ will loose the auction. In such a case Lemma 1 does not hold anymore and $W K$ can bid up to $R_{W K}$ even if she knows she is going to loose the auction for sure. This may change the whole equilibrium of the game.

Proceed again by backward induction; take any type $R_{W K}<R_{H}-\frac{B}{\beta}$, and suppose the outstanding bid $\left.b_{0}^{\mathrm{H}} \in\right] 0, R_{W K}[$. Such a $W K$ knows she will loose for sure the takeover contest, and according to Lemma 1, she would stay out of the auction. However, in exchange for a payment conditional on $W K$ making a bid, $W K$ now offers up to $b_{1}^{\mathrm{WK}}=R_{W K}$. The best reply of $W K$ to $b_{0}^{\mathrm{H}}$ at $t=1$ is then $b_{1}^{\mathrm{WK}}=R_{W K}, \forall R_{W K}$. 
This implies that now the function $t\left(b_{0}^{H}\right)$ becomes to $t\left(b_{0}^{H}\right)=b_{0}^{H}$. Let us then go back to (5); substituting for $t\left(b_{0}^{H}\right)=b_{0}^{H}$ we obtain the optimal (unconstrained) bid

$$
b_{0}^{\mathrm{H}}=\left(1-\frac{1}{2 p}\right) R_{H}
$$

while (6) still defines the Nash bargaining problem between $H$ and $I$. The solution $\delta_{0}$ of (6) is provided implicitly in Lemma 3 , and is certainly lying in the interval $] \frac{B}{\beta R_{H}}, 1[$.

When $\left(1-\frac{1}{2 p}\right)<\frac{B}{\beta R_{H}}$ the first bid of $H$ is equal to $\delta_{0} R_{H}$ for sure (as in the case without side payments). On the contrary, with high $p:\left(1-\frac{1}{2 p}\right)>\frac{B}{\beta R_{H}}$ the hostile bid is $b_{0}^{\mathrm{H}}=\max \left\{\left(1-\frac{1}{2 p}\right) R_{H}, \delta_{0} R_{H}\right\}$, where $\delta_{0}$ is the solution of $(6) . H$ is then pushed to offer in the first period a weakly higher bid compared to the case with no collusion.

\section{Conclusions}

In this paper we study takeover contests where an hostile raider, who initiate the takeover, compete against white knights involved by the target management. At each stage of the price negotiation we assume that the target management has the power to bargain with the potential bidders to set a minimum to the takeover price.

We find that the combination of these two anti-takeover devices - white knight intervention and managerial control over the bargaining process - may allow a white knight with synergies with the target firm lower than those of the hostile raider to actually win the takeover contest.

We design a takeover contest as a particular English auction where the bids at each round are negotiated by the target management with each of the bidders alternatively. While the idea of modeling the interaction between the target management and the bidder has been previously employed by Harris (1990), we are the first ones, to our knowledge, to combine the bargaining process with an English auction where the raider and the white knight compete one against the other for the control of the target company. Using this innovative framework we are able to characterize the conditions under which the possibility of a subsequent white knight intervention is sufficient to prevent a hostile bid. Moreover, we show that high initial unsolicited offers signals relatively low synergies by the raider who launched them.

The results of our basic model are robust if we consider an extension of the model allowing for collusion (ex-ante and ex-post) between the target firm and the white knight.

Finally, this paper sheds light on the mechanism leading to the determination of takeover bids and it helps to explain why only a few hostile bids occur (or win) when it is commonly believed that a firm can be protected by white knights. In this respect, the present paper contributes then to the current regulatory debate on the optimal design of anti-takeover devices. 


\section{References}

Andrade, G., M. Mitchell and E. Stafford (2001), "New Evidence and Perspectives on Mergers", Journal of Economic Perspectives, Vol. 15 (2), pp. 103-120.

Aktas, N., E. de Bodt and R. Roll (2008), "Negotiation under the threat of an auction: friendly deals, ex-ante competition and bid premiums", mimeo.

Banerjee, A. and J. E. Owers (1992), "Wealth Reduction in White Knight Bids", Financial Management, Vol. 21 (3), pp. 48-57.

Bennet, E. (1997), "Multilateral Bargaining Problems", Games and Economic Behavior, Vol. 19, pp. 151-179.

Boone, A. L. and J. H. Mulherin (2007), "How Are Firms Sold?", The Journal of Finance, Vol. 62 (2), pp. 847-875.

Burkart, M., D. Gromb and F. Panunzi (2000), "Agency Conflicts in Public and Negotiated Transfers of Corporate Control", The Journal of Finance, Vol. 55, pp. 647-672.

Burkart, M. and F. Panunzi (2006), "Takeovers" in Freixas, X., Ph. Hartmann, and C. Mayer (eds.) Financial Markets and Institutions: A European Perspective, pp. 265-297, Oxford University Press, Oxford, 2008.

Carroll, C., J.M. Griffith and P. M. Rudolph (1999), "The Performance of WhiteKnight Management", Financial Management, Vol. 27 (2), pp. 46-56.

Cosh, A. and P. Guest (2001), "The Long-run Performance of Hostile Takeovers: UK Evidence", ESRC Centre for Business Research University of Cambridge.

Eckbo, B. E. (2008), "Bidding strategies and takeover premiums: A review", Journal of Corporate Finance, forthcoming.

Franks, J. and C. Meyer (1996), "Hostile takeovers and the correction of managerial failure", Journal of Financial Economics, Vol. 40 (1), pp. 163-181.

Fridolfsson, S.O. and J. Stennek (2005), "Why Mergers Reduce Profits And Raise Share Prices: A Theory Of Preemptive Mergers", Journal of European Economic Association, Vol. 3 (5), pp. 1083-1104.

Harris, E. G. (1990), "Anti-takeover measures, Golden Parachutes, and Target Firm Shareholder Welfare", The Rand Journal of Economics, Vol. 21, pp. 614-625.

Hartzell, J. C., E. Ofek and D. Yermack (2004), "What's In It for Me? CEOs Whose Firms Are Acquired", The Reveiw of Financial Studies, Vol. 17, pp. 37-61.

Kästle, F. and B. Trappehl (2006), "Managing Hostile Take-overs: Poison Pills and White Knights", presentation for the DeutscherAnwaltVerein Arbeitsgemeinschaft Syndikusanwälte 13. Syndikusanwaltstag 9/10 November 2006, Berlin.

Manne, H. G. (1965), "Mergers and the market for corporate control", Journal of Political Economy, Vol. 73, pp. 110-120.

Martynova, M. and L. Renneboog (2006), "Mergers and Acquisition in Europe", ECGI Working Paper n. 114/2006.

Moeller, S. B., F. P. Schlingemann and R. M. Stulz (2005), "Wealth Distruction on a Massive Scale? A Study of Acquiring-firm Returns in the Recent Merger Wave", The Journal of Finance, Vol. 60 (2), pp. 757-782. 
Niden, C. M. (1993), "An Empirical Examination of White Knight Corporate Takeovers: Synergy and Overbidding", Financial Management, Vol. 22 (4), pp. 28-45.

Rosenkranz, S. (2005), "Bargaining in Mergers: The Role of outside options and termination provisions", Utrecht School of Economics, Tjalling C. Koopmans Research Institute Discussion Paper Series 05-32.

Shivdasani, A. (1993), "Board Composition, Ownership Structure, and Hostile Takeovers", Journal of Accounting and Economics, Vol. 16, pp. 167-198.

\section{Appendix}

Proof of Proposition 1: We already know the minimum bid the white knight has to offer for $I$ to be willing to consider it. Assume for the moment that any $W K$ with $R_{W K} \in\left[b_{0}^{\mathrm{H}}, R_{H}\right.$ [ is sure to win the takeover auction if she overbids $H$. In such a case $b_{1}$ must solve:

$$
\begin{aligned}
& \max _{b_{1}} \beta\left(R_{W K}-b_{1}\right) \operatorname{Pr}\left(W K \text { wins at bid } b_{1}\right) \\
& \max _{b_{1}} \beta\left(R_{W K}-b_{1}\right)
\end{aligned}
$$

whose solution is clearly the minimum bid $b_{1}$ that guarantees that $\operatorname{Pr}(W K$ wins at bid $b)=1$. But in order to have $\operatorname{Pr}(W K$ wins at bid $b)=1$, it must be that in the next round of bids, the hostile bidder will not be able to beat the outstanding bid $b_{1}$, i.e. he will not be able to counterbid. This is true if and only if in $t=2, \delta_{2}\left(b_{W K 1}\right) \geq 1$, that is if and only if the minimum acceptable bid requested by the target management in the next period is larger than the synergy $R_{H}$.

Formally, this is equivalent to the following condition on the white knight's winning bid

$$
b_{1}: \delta_{2}\left(b_{1}\right) \geq 1
$$

Last, the bid $b_{1}$ must also be higher than the outstanding hostile bid $b_{0}^{\mathrm{H}}$ :

$$
b_{1}>b_{0}^{\mathrm{H}}
$$

To derive the minimum $b_{1}$ such that $\delta_{2}\left(b_{1}\right) \geq 1$, we need to look at what would happen in the next bargaining round between the target management and the hostile bidder.

The Nash bargaining problem will look like ${ }^{17}$ :

$$
\max _{\delta_{2}}\left[\beta\left(1-\delta_{2}\right) R_{H}\right]\left[\delta_{2} \beta R_{H}-B-\left(\beta b_{1}\right)\right]
$$

so that

$$
\delta_{2}\left(b_{1}\right)=\frac{1}{2}+\frac{b_{1}}{2 R_{H}}+\frac{B}{2 \beta R_{H}}
$$

\footnotetext{
${ }^{17}$ If $I$ concludes the sale of $T$ with $H$ at $t=2$, he obtains the quota $\beta \delta_{2}$ of the total synergy $R_{H}$, but he loses his control of $T$, hence the private benefits $B$.
} 
and finally

$$
\begin{aligned}
\delta_{2}\left(b_{1}\right) & \geq 1 \\
& \Leftrightarrow b_{1} \geq R_{H}-\frac{B}{\beta}
\end{aligned}
$$

Notice that $\delta_{2}\left(b_{1}\right)$ is increasing in the bid $b_{1}$ hence any bid higher than $R_{H}-\frac{B}{\beta}$ deters $H$ from overbidding at $t=2$. Thus $R_{H}-\frac{B}{\beta}$ is the minimum bid that the white knight will need to offer in $t=1$ to ensure that his opponent $H$ cannot profitably overbid in the subsequent round.

Notice also that since $b_{1}$ is independent of $b_{0}^{\mathrm{H}}$, we do not need the exact expression of $b_{0}^{\mathrm{H}}$ to compute $\delta_{2}\left(b_{1}\right)$.

In conclusion, for the optimal WK's bid $\widehat{b}_{1}$ to ensure that the white knight wins the takeover contest at $t=1$, all the three conditions (3), (9) and (10), must be met.

Proof of Lemma 2: Putting together (3), (9) and (10) derived above it is clear that for the white knight to beat the raider and to take over $T$ it must be that $b_{1}^{*}=$ $\max \left\{R_{H}-\frac{B}{\beta}, b_{0}^{\mathrm{H}}, \delta_{1} R_{W K}\right\}$.

Computing the function $\delta_{1} R_{W K}=\frac{R_{W K}}{2}+\frac{b_{0}^{\mathrm{H}}}{2}-\frac{B}{2 \beta}$ at $b_{0}^{\mathrm{H}}=0$ gives us the intercept of $\delta_{1} R_{W K}$, and is then easy to see (fig. 2) that the lines $b_{1}^{*}=\delta_{1} R_{W K}$ and $b_{1}^{*}=b_{0}^{\mathrm{H}}$ cross at a point below $R_{H}-\frac{B}{\beta}$. Indeed, $\frac{1}{2}+\frac{b}{2 R_{W K}}-\frac{B}{2 \beta R_{W K}}=b$ for $b=R_{W K}-\frac{B}{\beta} \leq R_{H}-\frac{B}{\beta}$, by $R_{W K} \leq R_{H}$. Hence $\delta_{1} R_{W K}$ is always lower than $\max \left\{R_{H}-\frac{B}{\beta}, b_{0}^{\mathrm{H}}\right\}$.

Proof of Proposition 3: First, notice that for any triple of $(B, p, \beta), b_{0}^{*}=\delta_{0} R_{H}$, so that the comparative statics on $b_{0}^{*}$ coincide with the ones of $\delta_{0}$. We start studying the case $B<2 \beta R$, when $\delta_{0}=\frac{B}{\beta R_{H}}\left[1+p\left(1-\frac{B}{\beta R_{H}}\right)\right]$. It is immediate then to verify that:

$$
\begin{aligned}
& \frac{\partial \delta_{0}}{\partial p}>0 \\
& \frac{\partial \delta_{0}}{\partial B}>0 \\
& \frac{\partial \delta_{0}}{\partial \beta}<0
\end{aligned}
$$

For $B \in\left[\frac{\beta R_{H}}{2}, \beta R_{H}\right]$ the quota $\left.\delta_{0} \in\right] \frac{B}{\beta R_{H}}, 1[$ is implicitly defined by equation:

$$
1+\beta \frac{\left(1-\delta_{0}\right) R_{H}}{\delta_{0} \beta R_{H}-B}+\log \left(\frac{\left(1-\delta_{0}\right) R_{H}}{\delta_{0} \beta R R_{H}-B}\right)=\frac{1}{p\left(1-\delta_{0}\right)}
$$

For easiness of notation, define $\frac{\left(1-\delta_{0}\right) R_{H}}{\delta_{0} \beta R_{H}-B} \equiv X\left(\beta, B, \delta_{0}\right)$. By the implicit function theorem we obtain:

$$
\frac{\partial \delta_{0}}{\partial B}=-\frac{\left(\frac{1}{X}+\beta\right) \frac{\partial X}{\partial B}}{\left(\frac{1}{X} \frac{\partial X}{\partial \delta_{0}}+\beta \frac{\partial X}{\partial \delta_{0}}-\frac{\partial\left(\frac{1}{p\left(1-\delta_{0}\right)}\right)}{\partial \delta_{0}}\right)}
$$


where the denominator is negative since it is equal to the s.o.c. of the Nash bargaining problem. Hence,

$$
\operatorname{sgn}\left(\frac{\partial \delta_{0}}{\partial B}\right)=\operatorname{sgn}\left(\frac{1}{X}+\beta\right) \frac{\partial X}{\partial B}>0
$$

Analogously,

$$
\begin{aligned}
\frac{\partial \delta_{0}}{\partial \beta} & =-\frac{\left(\frac{1}{X}+\beta\right) \frac{\partial X}{\partial \beta}+X}{\left(\frac{1}{X} \frac{\partial X}{\partial \delta_{0}}+\beta \frac{\partial X}{\partial \delta_{0}}-\frac{\partial\left(\frac{1}{p\left(1-\delta_{0}\right)}\right)}{\partial \delta_{0}}\right)} \\
& \Rightarrow \operatorname{sgn}\left(\frac{\partial \delta_{0}}{\partial B}\right)=\operatorname{sgn}\left(\left(\frac{1}{X}+\beta\right) \frac{\partial X}{\partial \beta}+X\right)
\end{aligned}
$$

and explicitly computing

$$
\begin{aligned}
\left(\frac{1}{X}+\beta\right) \frac{\partial X}{\partial \beta}+X & =\frac{-\delta_{0}\left(1-\delta_{0}\right) R_{H}^{2}}{\left(\delta_{0} \beta R_{H}-B\right)^{2}}\left(\frac{1}{X}+\beta\right)+\frac{\left(1-\delta_{0}\right) R_{H}}{\delta_{0} \beta R_{H}-B} \\
& =\frac{\left(1-\delta_{0}\right) R_{H}}{\delta_{0} \beta R_{H}-B}\left(1-\frac{\delta_{0} R_{H}}{\delta_{0} \beta R_{H}-B}\left(\frac{1}{X}+\beta\right)\right) \\
& =\frac{\left(1-\delta_{0}\right) R_{H}}{\delta_{0} \beta R_{H}-B}\left(1-\frac{\delta_{0} R_{H}}{\delta_{0} \beta R_{H}-B}\left(\frac{\delta_{0} \beta R_{H}-B}{\left(1-\delta_{0}\right) R_{H}}+\beta\right)\right) \\
& =\frac{\left(1-\delta_{0}\right) R_{H}}{\delta_{0} \beta R_{H}-B}\left(1-\frac{\delta_{0} R_{H}}{\left(1-\delta_{0}\right) R_{H}}-\frac{\beta \delta_{0} R_{H}}{\delta_{0} \beta R_{H}-B}\right)<0
\end{aligned}
$$

since $\frac{\beta \delta_{0} R_{H}}{\delta_{0} \beta R_{H}-B}>1$ and $\frac{\left(1-\delta_{0}\right) R_{H}}{\delta_{0} \beta R_{H}-B}>0$. Thus $\frac{\partial \delta_{0}}{\partial \beta}<0$.

Finally:

$$
\begin{aligned}
\frac{\partial \delta_{0}}{\partial p} & =\frac{\frac{\partial\left(\frac{1}{p\left(1-\delta_{0}\right)}\right)}{\partial p}}{\left(\frac{1}{X} \frac{\partial X}{\partial \delta_{0}}+\beta \frac{\partial X}{\partial \delta_{0}}-\frac{\partial\left(\frac{1}{p\left(1-\delta_{0}\right)}\right)}{\partial \delta_{0}}\right)} \\
& \Rightarrow \operatorname{sgn}\left(\frac{\partial \delta_{0}}{\partial p}\right)=\operatorname{sgn}\left(\frac{\partial\left(-\frac{1}{p\left(1-\delta_{0}\right)}\right)}{\partial p}\right)>0
\end{aligned}
$$

that concludes our proof. 